\title{
Use of butorphanol and diprenorphine to counter respiratory impairment in the immobilised white rhinoceros (Ceratotherium simum)
}

\begin{tabular}{|c|c|}
\hline \multicolumn{2}{|l|}{$\begin{array}{l}\text { Authors: } \\
\text { Leith C.R. Meye } \\
\text { Andrea Fuller }{ }^{1,2} \\
\text { Markus Hofme } \\
\text { Peter Buss } 4,5 \\
\text { Michele Miller }^{6} \\
\text { Anna Haw }{ }^{2}\end{array}$} \\
\hline $\begin{array}{l}\text { Sciences, University of } \\
\text { Pretoria, South Africa }\end{array}$ & $\begin{array}{l}\text { f Paraclinical } \\
\text { ersity of } \\
\text { Africa }\end{array}$ \\
\hline \multicolumn{2}{|c|}{$\begin{array}{l}{ }^{2} \text { School of Physiology, } \\
\text { University of the } \\
\text { Witwatersrand, South Africa }\end{array}$} \\
\hline \multicolumn{2}{|c|}{$\begin{array}{l}{ }^{3} \text { Great Plains Conservation } \\
\text { and Rhino without Borders, } \\
\text { Maun, Botswana }\end{array}$} \\
\hline \multicolumn{2}{|c|}{$\begin{array}{l}{ }^{4} \text { Veterinary Wildlife Services, } \\
\text { South African National Parks, } \\
\text { South Africa }\end{array}$} \\
\hline \multicolumn{2}{|c|}{$\begin{array}{l}{ }^{5} \text { Department of Production } \\
\text { Animal Studies, University } \\
\text { of Pretoria, South Africa }\end{array}$} \\
\hline \multicolumn{2}{|c|}{$\begin{array}{l}{ }^{6} \text { Division of Molecular } \\
\text { Biology and Human Genetics, } \\
\text { Stellenbosch University, } \\
\text { South Africa }\end{array}$} \\
\hline \multicolumn{2}{|c|}{$\begin{array}{l}\text { Corresponding author: } \\
\text { Leith Meyer, } \\
\text { leith.meyer@up.ac.za }\end{array}$} \\
\hline \multicolumn{2}{|c|}{$\begin{array}{l}\text { Dates: } \\
\text { Received: } 11 \text { Apr. } 2018 \\
\text { Accepted: } 04 \text { Sept. } 2018 \\
\text { Published: } 18 \text { Oct. } 2018\end{array}$} \\
\hline \multicolumn{2}{|l|}{ Read online: } \\
\hline 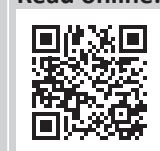 & $\begin{array}{l}\text { Scan this QR } \\
\text { code with your } \\
\text { smart phone or } \\
\text { mobile device } \\
\text { to read online. }\end{array}$ \\
\hline
\end{tabular}

Opioid-induced immobilisation results in severe respiratory impairment in the white rhinoceros. It has therefore been attempted in the field to reverse this impairment with the use of opioid agonist-antagonists, such as nalorphine, nalbuphine, butorphanol and diprenorphine; however, the efficacy of some of these treatments has yet to be determined. The efficacy of butorphanol, either alone or in combination with diprenorphine both with and without oxygen insufflation, in alleviating opioid-induced respiratory impairment was evaluated. The study was performed in two parts: a boma trial and a field trial. Rhinoceroses were immobilised specifically for the study, according to a strict protocol to minimise confounding variables. A two-way analysis of variance was used to compare the physiological responses of the rhinoceroses to the different treatments and their effects over time. The intravenous administration of butorphanol (at $3.3 \mathrm{mg}$ per $\mathrm{mg}$ etorphine) plus diprenorphine (at $0.4 \mathrm{mg}$ per mg etorphine) did not offer any advantage over butorphanol (at $15 \mathrm{mg}$ per $\mathrm{mg}$ etorphine) alone with regard to improving $\mathrm{P}_{\mathrm{a}} \mathrm{O}_{2}, \mathrm{P}_{\mathrm{a}} \mathrm{CO}_{2}$ and respiratory rates in etorphine-immobilised white rhinoceroses. Both butorphanol + diprenorphine + oxygen and butorphanol + oxygen, at the doses used, significantly improved the etorphine-induced hypoxaemia in both bomaand field-immobilised white rhinoceroses. Clinically acceptable oxygenation in fieldimmobilised white rhinoceroses can be achieved by using either treatment regimen, provided that it is combined with oxygen insufflation.

\section{Introduction}

The ability to safely immobilise white rhinoceroses for management procedures such as translocation, veterinary treatments and fitting of tracking devices is essential for the long-term survival of these mega-herbivores, especially with increased poaching pressure. The advent of potent mu-opioid agonists, such as etorphine hydrochloride, significantly decreased the mortality rate of rhinoceroses during capture events (Alford, Burkhart \& Johnson 1974). However, a drawback of the use of potent opioid agonists is that they impair respiration profoundly, especially in the white rhinoceros (Burroughs et al. 2012a).

Over the last 40 years, wildlife veterinarians have used opioid agonist-antagonists such as nalorphine, nalbuphine, butorphanol and diprenorphine in an attempt to reverse respiratory impairment when etorphine is used while maintaining adequate immobilisation (Boardman et al. 2014; Burroughs et al. 2012a; Bush et al. 2004; Fahlman 2008; Miller et al. 2013; Wenger et al. 2007). Before 2001, nalorphine was readily available in South Africa and the combination of nalorphine with diprenorphine for the partial antagonism of etorphine in white rhinoceroses was a protocol used in the Kruger National Park (Markus Hofmeyr, pers. comm., 23 Feb. 2012). However, the physiological benefits of administering this combination had never been scientifically evaluated, and even when nalorphine was used on its own as a partial antagonist in immobilised rhinoceroses, it only slightly improved blood oxygenation (Bush et al. 2004). Today, butorphanol and diprenorphine are the most widely accessible of the opioid agonist-antagonists, but conflicting opinions exist as to which drug, or combination of drugs, provides the best respiratory support for immobilised white rhinoceroses. As nalorphine is not available, some veterinarians now use a combination of diprenorphine and butorphanol. We hypothesised that butorphanol with diprenorphine would reduce respiratory impairment to the same extent as butorphanol (without diprenorphine) whether or not oxygen insufflation was administered.

How to cite this article: Meyer, L.C.R., Fuller, A., Hofmeyr, M., Buss, P., Miller, M. \& Haw, A., 2018, 'Use of butorphanol and diprenorphine to counter respiratory impairment in the immobilised white rhinoceros (Ceratotherium simum)', Journal of the South African Veterinary Association 89(0), a1683. https://doi.org/10.4102/jsava.v89i0.1683

Copyright: ( $)$ 2018. The Authors. Licensee: AOSIS. This work is licensed under the Creative Commons Attribution License. 


\section{Research method and design}

The project was divided into two parts: a boma study and a field study.

\section{Boma study: Study area and sample population}

Eight sub-adult male white rhinoceroses were captured in the Kruger National Park (24.98984 S, 31.59263 E, alt. 1020 m) and housed individually in bomas. Husbandry procedures as per the South African National Parks (SANParks) standard operating procedures (SOPs) for boma-kept rhinoceroses were carried out throughout the experimental period. The trial started after a 1-month adaptation period and data collection occurred from August to December 2012. All immobilisations took place in the morning (between 05:20 and 10:50) and barometric pressure ranged from $737.0 \mathrm{mmHg}$ to $745.9 \mathrm{mmHg}$.

\section{Chemical immobilisation and experimental interventions}

At each trial, the rhinoceros was immobilised with a combination of $2 \mathrm{mg}-3 \mathrm{mg}$ etorphine hydrochloride (dose range $2.0 \mu \mathrm{g} / \mathrm{kg}-2.6 \mu \mathrm{g} / \mathrm{kg}$ ) (M99 ${ }^{\circledR}$, Novartis, Kempton Park, South Africa, $9.8 \mathrm{mg} / \mathrm{mL}$ ), $30 \mathrm{mg}$ - $45 \mathrm{mg}$ azaperone (dose range $30 \mu \mathrm{g} / \mathrm{kg}-40 \mu \mathrm{g} / \mathrm{kg}$ ) (Stressnil ${ }^{\circledR}$, Janssen Pharmaceutical Ltd., Halfway House, South Africa, $40 \mathrm{mg} / \mathrm{mL}$ ) and 2500 international units (i.u). hyaluronidase (lyophilised hyalase, Kyron Laboratories, Benrose, South Africa). The dosage of the drug was calculated from the previously measured body mass according to a standardised dose table (Haw et al. 2014). Immobilising drugs were administered into the nuchal hump using a $3 \mathrm{~mL}$ plastic dart with a $60 \mathrm{~mm}$ needle, powered by a $\mathrm{CO}_{2}$-powered dart-gun (Dan-Inject, South Africa) as described previously (Haw et al. 2014). Once the rhinoceros was immobilised, it was blindfolded and positioned in lateral recumbency (Time 0). Trials were performed only if the animal became recumbent within 15 min of darting, and position was altered between left and right lateral recumbency at each immobilisation.

The experiment consisted of five trials with the following interventions (Table 1): butorphanol IV (15 mg per mg etorphine, mean dose $33 \mu \mathrm{g} / \mathrm{kg}$, Kyron Laboratories, $20 \mathrm{mg}$ / $\mathrm{mL}$ ) (But), butorphanol IV (3.3 mg per mg etorphine, mean dose $7.5 \mu \mathrm{g} / \mathrm{kg})+$ diprenorphine IV ( $0.4 \mathrm{mg}$ per mg etorphine, mean dose $0.89 \mu \mathrm{g} / \mathrm{kg}$, M5050 ${ }^{\circledR}$, Novartis, $12 \mathrm{mg} / \mathrm{mL}$ ) (But+M5050), butorphanol IV (15 mg per mg etorphine) + oxygen intra-tracheal insufflation (AFROX, Johannesburg, South Africa, $30 \mathrm{~L} / \mathrm{min})\left(\right.$ But $\left.+\mathrm{O}_{2}\right)$, butorphanol IV (3.3 mg per $\mathrm{mg}$ etorphine) + diprenorphine IV (0.4 mg per $\mathrm{mg}$ etorphine) + oxygen intra-tracheal insufflation $(30 \mathrm{~L} / \mathrm{min})$ (But+M5050+O $\mathrm{O}_{2}$ ) and sterile water (control) were evaluated and compared as measures to support the respiratory physiology of the immobilised white rhinoceros.

Each rhinoceros received each intervention for the five trials in a randomised order at 2-week intervals. The interventions were administered $6 \mathrm{~min}$ after the rhinoceros became
TABLE 1: Drugs and doses used to treat respiratory impairment in the rhinoceros.

\begin{tabular}{|c|c|}
\hline Treatment intervention & Abbreviation \\
\hline Butorphanol (15 mg/mg etorphine) $(1.50 \mathrm{~mL}-2.25 \mathrm{~mL})$ & But \\
\hline $\begin{array}{l}\text { Butorphanol ( } 3.3 \mathrm{mg} / \mathrm{mg} \text { etorphine })+ \text { diprenorphine } \\
(0.4 \mathrm{mg} / \mathrm{mg} \text { etorphine) }(0.40 \mathrm{~mL}-0.55 \mathrm{~mL})\end{array}$ & But+M5050 \\
\hline Butorphanol (15 mg/mg etorphine) + oxygen (30 L/min) & $\mathrm{But}+\mathrm{O}_{2}$ \\
\hline $\begin{array}{l}\text { Butorphanol }(3.3 \mathrm{mg} / \mathrm{mg} \text { etorphine })+\text { diprenorphine } \\
(0.4 \mathrm{mg} / \mathrm{mg} \text { etorphine })+\text { oxygen }(30 \mathrm{~L} / \mathrm{min})\end{array}$ & But $+\mathrm{M} 5050+\mathrm{O}_{2}$ \\
\hline Sterile water $(2 \mathrm{~mL})$ & Control \\
\hline
\end{tabular}

laterally recumbent. Clinical data and samples were collected at 5 min after the animal became laterally recumbent (before the intervention) and every $5 \mathrm{~min}$ thereafter for a 20-min immobilisation period. In the control trial, butorphanol (15 $\mathrm{mg}$ per $\mathrm{mg}$ etorphine) was administered at $21 \mathrm{~min}$ to facilitate arousal and loading into a crate.

\section{Clinical monitoring and data collection}

Respiratory rate (breaths per minute) was monitored by counting thoracic and abdominal excursions and feeling for expired air at the nares. An immobilisation score, ranging from 1 (no immobilising or sedative effect) to 6 (excessive immobilisation depth with respiration $<3$ breaths $/ \mathrm{min}$ ), was used to assess the level of immobilisation at 5, 10, 15 and $20 \mathrm{~min}$. Level 3 indicated standing sedation that allowed handling, while levels 4 and 5 indicated recumbent immobilisation with or without ear movement, respectively.

Arterial blood samples for blood gas analyses were collected from the medial auricular artery catheterised with a $22 \mathrm{G} \times 1$ " IV catheter (Nipro Safelet Cath, Nipro Corporation, Bridgewater, NJ). A $0.5 \mathrm{~mL}$ sample was collected anaerobically into $1 \mathrm{~mL}$ heparinised syringes at 5, 10, 15 and $20 \mathrm{~min}$ after the rhinoceros became laterally recumbent. Partial pressures of carbon dioxide $\left(\mathrm{P}_{\mathrm{a}} \mathrm{CO}_{2}\right)$ and oxygen $\left(\mathrm{P}_{\mathrm{a}} \mathrm{O}_{2}\right)$ were measured immediately using a portable pre-calibrated blood gas analyser with pre-calibrated blood gas cassettes (Roche OPTI CCA Analyzer + OPTI cassette B, Kat Medical, Johannesburg, South Africa). The blood gas variables are reported at a body temperature of $37^{\circ} \mathrm{C}$. Body temperature was measured with a thermocouple thermometer (BAT-12, Physitemp Instruments Clifton, New Jersey, United States [US]) probe inserted $10 \mathrm{~cm}$ into the rectum.

In the trials in which oxygen was administered, the oxygen was delivered at a constant flow rate of $30 \mathrm{~L} / \mathrm{min}$ via nasotracheal intubation using an equine stomach tube (9.5 mm od $\times 213 \mathrm{~cm}$, Kyron Laboratories) as described by Bush et al. (2004).

Twenty-one minutes into the recumbent period, the rhinoceros was stimulated to stand and was guided into a crate for weighing using a scale suspended from a vehiclemounted crane. Approximately $35 \mathrm{~min}$ after the animal became laterally recumbent, the effects of etorphine were reversed using naltrexone $(50 \mathrm{mg} / \mathrm{mL}$, Kyron Laboratories) administered intravenously into an auricular vein at 20 times the etorphine dose. The rhinoceros was then released from the crate into its boma. 
All rhinoceroses used in these trials were monitored using a standardised boma scoring system on a daily basis for changes in appetite, defaecation and behaviour (Miller et al. 2016). In addition, haematological and biochemical analyses were performed at the time of each immobilisation to assess any changes in health status.

\section{Field: Study area and sample population}

The study animals were 22 sub-adult male white rhinoceroses, which were immobilised in Kruger National Park in February 2013 during which time barometric pressures ranged from $717.1 \mathrm{mmHg}$ to $748.3 \mathrm{mmHg}$. All animals appeared healthy based on body condition and physical examination. As in the boma study, all rhinoceroses were immobilised with a combination of etorphine hydrochloride, azaperone and hyaluronidase and drug doses were calculated on estimated body mass according to the same dose table as used in the boma study. Animals were located and darted using a helicopter. Immobilising drugs were delivered remotely using the same darting equipment as in the boma study. If animals were not recumbent within 15 min of darting, they were excluded from the trial and the effects of the immobilising agent reversed immediately. As butorphanol used alone without oxygen, and butorphanol plus diprenorphine without oxygen, did not completely reverse hypoxaemia in the boma part of the study, it was decided not to test drug effects without oxygen supplementation in the field. Therefore, $6 \mathrm{~min}$ into the immobilisation period, the following interventions were performed: 14 rhinoceroses received But $+\mathrm{O}_{2}$ and 8 rhinoceroses received But $+\mathrm{M} 5050+\mathrm{O}_{2}$.

Clinical monitoring was carried out as in the boma study, but the immobilisation period was extended to $25 \mathrm{~min}$; thus, an extra arterial blood sample and a set of recordings were taken at that time. The arterial blood samples were analysed using a portable pre-calibrated blood gas analyser with recalibrated test cards $\left(\right.$ EPOC $^{\circledR}$ Portable analyser system + EPOC ${ }^{\circledR}$ BGEM test cards, Kyron Laboratories, Johannesburg, South Africa).

Twenty-six minutes into the recumbent period, the rhinoceros was stimulated to stand and walk into a weighing crate and body mass was recorded. Approximately $40 \mathrm{~min}$ after the rhinoceros became laterally recumbent, the effects of etorphine were completely reversed using the pure opioid antagonist naltrexone, administered intravenously into an auricular vein at $20 \mathrm{mg}$ per $\mathrm{mg}$ etorphine. The rhinoceros was then released from the weighing crate.

\section{Data analysis}

We used GraphPad Prism version 6.00 for Mac OS X (GraphPad Software Inc., San Diego, California, US) for statistical analyses. All results are reported as mean $\pm \mathrm{SD}$, and $p<0.05$ was considered statistically significant. For the boma study, we used a repeated measures two-way analysis of variance (ANOVA) followed by Tukey's multiple comparisons for two separate analyses. In the first analysis, we looked for differences between responses to But, But+M5050 and sterile water (control) at 5, 10, 15 and $20 \mathrm{~min}$ (trials without oxygen), while in the second analysis we looked for differences between responses to But $+\mathrm{O}_{2}$, But $+\mathrm{M} 5050+\mathrm{O}_{2}$ and sterile water (control) at 5, 10, 15 and $20 \mathrm{~min}$ (trials with oxygen). For the field study, we used a two-way ANOVA followed by Sidak's multiple comparisons test to test for differences between responses to $\mathrm{But}+\mathrm{O}_{2}$ and But $+\mathrm{M} 5050+\mathrm{O}_{2}$ at 5, 10, 15, 20 and $25 \mathrm{~min}$. A Tukey's post-hoc test was used to test for differences in values between time points within each trial.

\section{Ethical consideration}

This project was approved by the Animal Use and Care Committee (approval HAWA1042) of South African National Parks (SANParks) as well as the Animal Ethics Committees of the University of the Witwatersrand (approval no. 2012/23/04) and the University of Pretoria (approval no. V087/13).

\section{Results}

All boma-housed rhinoceroses were in good health, indicated by normal demeanour and normal eating and defaecation habits throughout the study period. Field rhinoceroses were also in good health at the time of darting, determined by observing normal behaviour from the helicopter before darting and evaluating body condition score. Each animal's health status was confirmed by subsequent haematology and biochemistry analysis of blood samples collected at the time of each immobilisation. Rectal temperatures for bomaimmobilised rhinoceroses ranged from $36.7^{\circ} \mathrm{C}$ to $39.0^{\circ} \mathrm{C}$ and $37.6{ }^{\circ} \mathrm{C}$ to $38.5{ }^{\circ} \mathrm{C}$ for field-immobilised rhinoceroses. The average body mass of the boma rhinoceroses was $1220 \mathrm{~kg} \pm$ $148 \mathrm{~kg}$. In the field study, the average body mass for the But $+\mathrm{O}_{2}$ group $(n=14)$ was $1272 \mathrm{~kg} \pm 227 \mathrm{~kg}$, while that for the But $+\mathrm{M} 5050+\mathrm{O}_{2}$ group $(n=8)$ was $1336 \mathrm{~kg} \pm 339 \mathrm{~kg}$. Most field rhinoceroses were estimated to be in the correct body mass bracket according to the dose table (Haw et al. 2014), although four rhinoceroses in the But+M5050+ $\mathrm{O}_{2}$ group were estimated to be in one bracket lower than their actual mass. Despite the lower than recommended dose of etorphine, these rhinoceroses were immobile within $15 \mathrm{~min}$ of darting. Etorphine doses ranged from $2.0 \mathrm{mg}$ to $3.5 \mathrm{mg}$ and azaperone $30.0 \mathrm{mg}$ to $52.5 \mathrm{mg}$. Hyaluronidase was kept constant at 2500 i.u. for each rhinoceros. The level of immobilisation did not change between the trials as the median immobilisation score at all time points across all trials was 4 (recumbent with ear movements). No acute mortality occurred in the rhinoceroses that were studied.

\section{Boma study}

Chemical immobilisation resulted in severe hypoxaemia in all trials (Figure 1a and Figure 2a). At $5 \mathrm{~min}$, the rhinoceroses had similar $\mathrm{P}_{\mathrm{a}} \mathrm{O}_{2}$ values $(p>0.05)$ of $27 \mathrm{mmHg} \pm 7 \mathrm{mmHg}$ (control), $28 \mathrm{mmHg} \pm 4 \mathrm{mmHg}$ (But), $30 \mathrm{mmHg} \pm 6 \mathrm{mmHg}$ (But+M5050), $31 \mathrm{mmHg} \pm 6 \mathrm{mmHg}\left(\mathrm{But}+\mathrm{O}_{2}\right)$ and $30 \mathrm{mmHg}$ 

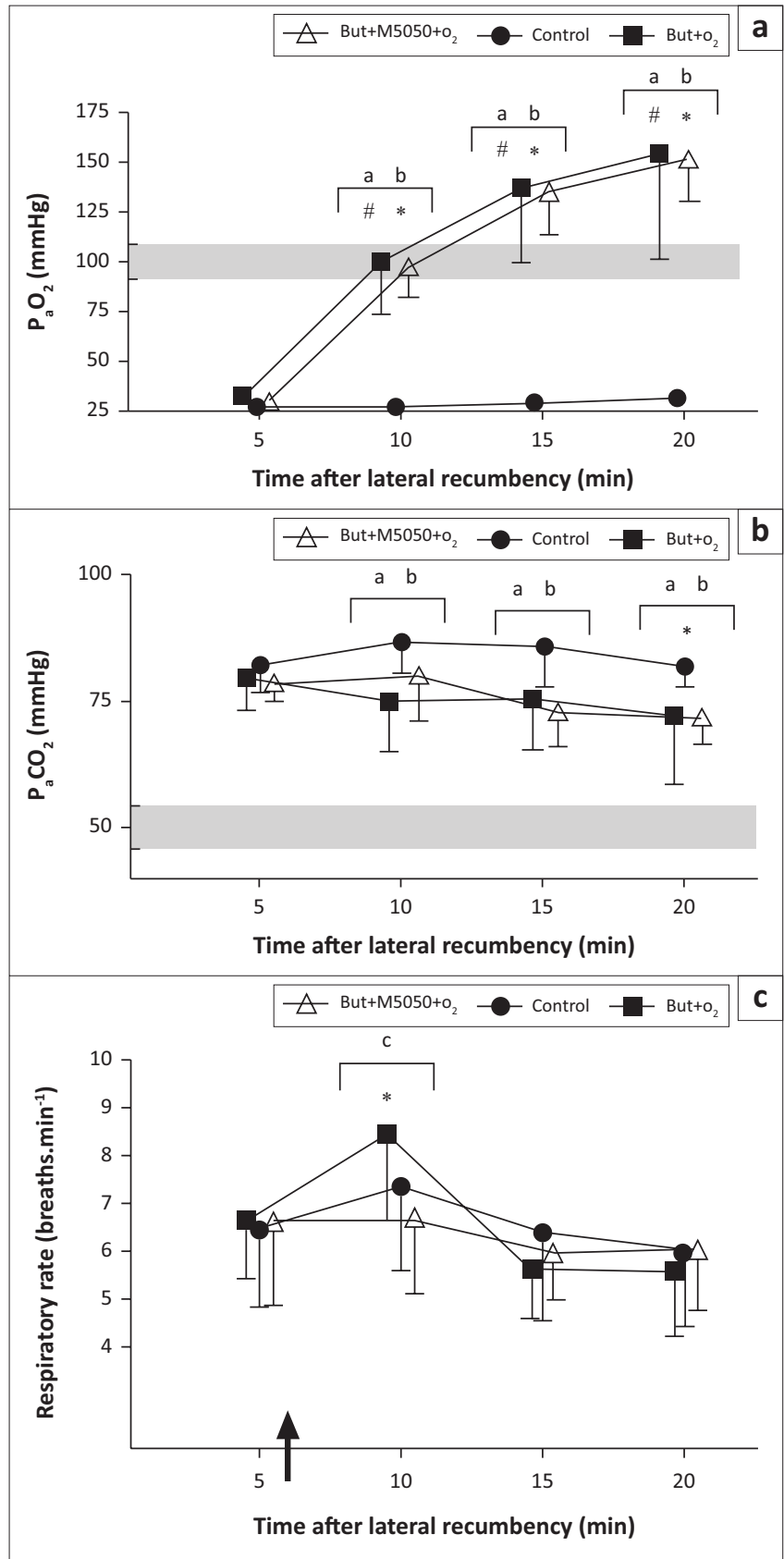

The black arrow indicates the time at which the partial antagonists were administered and oxygen insufflation initiated.

Note: ' $a$ ' and ' $b$ ', indicate the time points at which the But $+\mathrm{O}_{2}$ and the But $+\mathrm{M} 5050+\mathrm{O}_{2}$ trials differed from the control trial, respectively; and ' $c$ ' shows the time points at which the

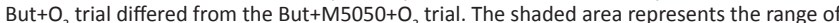
normal values in standing, unrestrained white rhinoceros.

*, Values in the $\mathrm{But}+\mathrm{O}_{2}$ trial that differ from pre-intervention values (5 min).

\#, Values in the But+M5050+O trial that differ from values at $5 \mathrm{~min}$.

Source: Citino, S.B. \& Bush, M., 2007 'Reference cardiopulmonary physiologic parameters for standing, unrestrained white rhinoceroses (Ceratotherium simum)', Journal of Zoo and Wildlife Medicine 38, 375-379. https://doi.org/10.1638/2006-0007R1.1

FIGURE 1: Boma study - Treatments with oxygen. (a) Partial pressure of arterial oxygen $\left(\mathrm{P}_{2} \mathrm{O}_{2}\right)$, (b) partial pressure of arterial carbon dioxide $\left(\mathrm{P}_{2} \mathrm{CO}_{2}\right)$ and (c) respiratory rate (breaths per minute) of boma-immobilised rhinoceros given intravenous butorphanol + oxygen insufflation (But $+0, n=8$ ), intravenous butorphanol + diprenorphine + oxygen insufflation (But $+\mathrm{M} 5050+\mathrm{O}_{2}, n=8$ ) and sterile water (control, $n=8$ ). Mean and standard deviations shown.

$\pm 7 \mathrm{mmHg}\left(\mathrm{But}+\mathrm{M} 5050+\mathrm{O}_{2}\right) . \mathrm{P}_{\mathrm{a}} \mathrm{O}_{2}$ in the rhinoceroses then changed over time in both sets of trials, namely, the trials without oxygen $\left(F_{(3,21)}=216.3, p<0.0001\right)$ and with oxygen $\left(F_{(3,2)}=81.64, p<0.0001\right)$. At the time points following the treatment interventions, $\mathrm{P}_{\mathrm{a}} \mathrm{O}_{2}$ differed amongst the trials
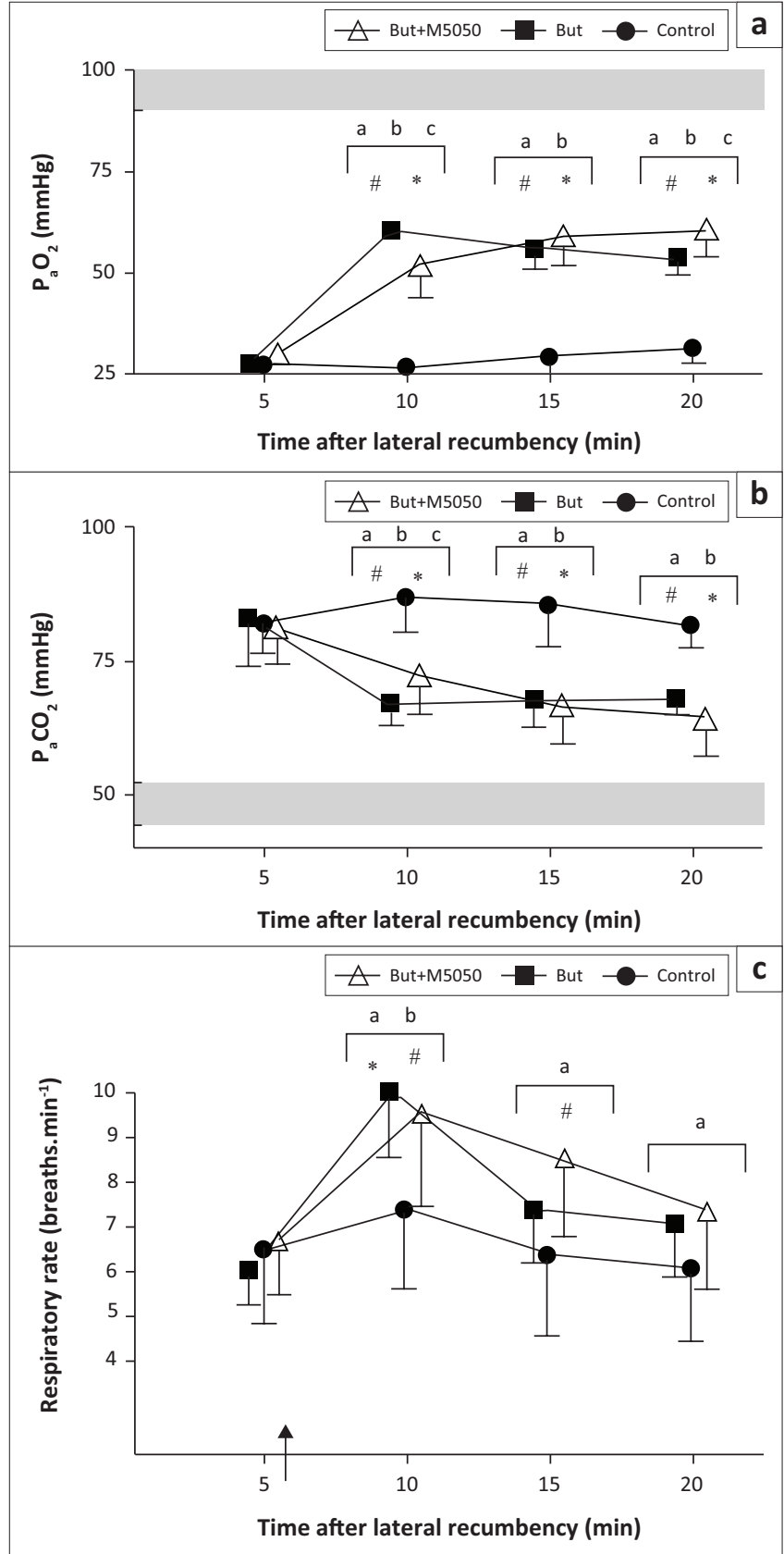

The black arrow indicates the time at which the partial antagonists were administered.

Note: ' $a$ ' and ' $b$ ', indicate the time points at which the But+M5050 and the But trials differed from the control trial, respectively; and ' $c$ ' shows the time points at which the But+M5050 trial differed from the But trial.

The shaded area represents the range of normal values in standing, unrestrained white rhinoceros.

*, Values in the But trial that differ from pre-intervention values ( $5 \mathrm{~min}$ ).

\#, Values in the But+M5050 trial that differ from values at $5 \mathrm{~min}$

Source: Citino, S.B. \& Bush, M., 2007 'Reference cardiopulmonary physiologic parameters for standing, unrestrained white rhinoceroses (Ceratotherium simum)', Journal of Zoo and Wildlife Medicine 38, 375-379. https://doi.org/10.1638/2006-0007R1.1

FIGURE 2: Boma study - Treatments without oxygen. (a) Partial pressure of arterial oxygen $\left(\mathrm{P}_{\mathrm{a}} \mathrm{O}_{2}\right)$, (b) partial pressure of arterial carbon dioxide $\left(\mathrm{P}_{\mathrm{a}} \mathrm{CO}_{2}\right)$ and (c) respiratory rate (breaths per minute) of boma-immobilised rhinoceros given intravenous butorphanol (But, $n=8$ ), intravenous butorphanol + diprenorphine (But+M5050, $n=8$ ) and sterile water (control, $n=8$ ). Mean and standard deviations shown.

without oxygen $\left(F_{(2,14)}=125.2, p<0.0001\right)$ as well as those with oxygen supplementation $\left(F_{(2,14)}=49.52, p<0.0001\right)$. Both But and But+M5050 led to improved oxygenation at 10,15 and $20 \mathrm{~min}$ compared to the control trial, but the rhinoceroses were still hypoxaemic at $20 \mathrm{~min}\left(\mathrm{P}_{\mathrm{a}} \mathrm{O}_{2}=\right.$ 
$54 \mathrm{mmHg} \pm 4 \mathrm{mmHg}$ and $61 \mathrm{mmHg} \pm 6 \mathrm{mmHg}$ in the But and But $+\mathrm{M} 5050$ trials, respectively). Similarly, both But $+\mathrm{O}_{2}$ and But $+\mathrm{M} 5050+\mathrm{O}_{2}$ treatments led to improved oxygenation at 10,15 and 20 min compared to the control trial, but unlike the treatments without oxygen, these treatments completely corrected the etorphine-induced hypoxaemia. In these two trials with oxygen, the rhinoceroses had $\mathrm{P}_{\mathrm{a}} \mathrm{O}_{2}$ values of $154 \mathrm{mmHg} \pm 53 \mathrm{mmHg}\left(\right.$ But $\left.+\mathrm{O}_{2}\right)$ and $152 \mathrm{mmHg} \pm 21 \mathrm{mmHg}$ (But+M5050 $+\mathrm{O}_{2}$ ) at $20 \mathrm{~min}$. Throughout the immobilisation period, both the $\mathrm{But}+\mathrm{O}_{2}$ and $\mathrm{But}+\mathrm{M} 5050+\mathrm{O}_{2}$ treatment interventions led to similar $\mathrm{P}_{2} \mathrm{O}_{2}$ values in the rhinoceroses $(p>0.05)$. On the other hand, $\mathrm{P}_{\mathrm{a}} \mathrm{O}_{2}$ values in the But and But+M5050 trials were statistically different at $10 \mathrm{~min}$ $(60 \mathrm{mmHg} \pm 3 \mathrm{mmHg}$ [But] and $52 \mathrm{mmHg} \pm 8 \mathrm{mmHg}$ [But+M5050], $p<0.001)$ and $20 \mathrm{~min}(54 \mathrm{mmHg} \pm 4 \mathrm{mmHg}$ [But] and $61 \mathrm{mmHg} \pm 6 \mathrm{mmHg}$ [But+M5050], $p<0001)$, but not at $15 \min (p>0.05)$.

All rhinoceroses had similarly elevated $\mathrm{P}_{\mathrm{a}} \mathrm{CO}_{2}$ values at $5 \mathrm{~min}$ of $82 \mathrm{mmHg} \pm 6 \mathrm{mmHg}$ (control), $83 \mathrm{mmHg} \pm$ $9 \mathrm{mmHg}$ (But), $81 \mathrm{mmHg} \pm 7 \mathrm{mmHg}$ (But+M5050), 79 $\mathrm{mmHg} \pm 7 \mathrm{mmHg}\left(\right.$ But $\left.+\mathrm{O}_{2}\right)$ and $72 \mathrm{mmHg} \pm 5 \mathrm{mmHg}$ (But+M5050+O $\mathrm{O}_{2}$ ) (Figure $1 \mathrm{~b}$ and Figure $2 \mathrm{~b}$ ). $\mathrm{PCO}_{2}$ then changed over time in the trials without oxygen $\left(F_{(3,21)}=20.8\right.$, $p<0.0001)$ and those with oxygen $\left(F_{(3,21)}=4.61, p=0.01\right)$. $\mathrm{P}_{\mathrm{a}} \mathrm{CO}_{2}$ in the rhinoceroses also changed amongst treatment groups in the two sets of trials $\left(F_{(2,14)}=34.16, p<0.0001\right.$ [trials without oxygen] $)$ and $\left(F_{(2,14)}=8.78, p=0.003\right.$ [trials with oxygen]). The treatment interventions led to lower $\mathrm{P}_{\mathrm{a}} \mathrm{CO}_{2}$ values in the rhinoceroses compared to when no treatment was administered (control) at all time points following the interventions, and by the end of the immobilisation period, $\mathrm{P}_{\mathrm{a}} \mathrm{CO}_{2}$ values in the rhinoceroses that received treatments were lower compared to those at $5 \mathrm{~min}(p<0.05)$. At $20 \mathrm{~min}$, the rhinoceroses had $\mathrm{P}_{\mathrm{a}} \mathrm{CO}_{2}$ values of $82 \mathrm{mmHg} \pm 4 \mathrm{mmHg}$ (control), $68 \mathrm{mmHg} \pm$ $3 \mathrm{mmHg}$ (But), $64 \mathrm{mmHg} \pm 7 \mathrm{mmHg}$ (But+M5050), $72 \mathrm{mmHg} \pm 13 \mathrm{mmHg}\left(\mathrm{But}+\mathrm{O}_{2}\right)$ and $72 \mathrm{mmHg} \pm 5 \mathrm{mmHg}$ $\left(\right.$ But $\left.+\mathrm{M} 5050+\mathrm{O}_{2}\right)$. Throughout the immobilisation period, there were no differences in the rhinoceroses' $\mathrm{P}_{\mathrm{a}} \mathrm{CO}_{2}$ values between the But and But+M5050 trials (apart from $10 \mathrm{~min}$, $p<0.05)$, nor the But $+\mathrm{O}_{2}$ and But $+\mathrm{M} 5050+\mathrm{O}_{2}$ trials $(p>0.05)$.

At $5 \mathrm{~min}$, the respiratory rates in the rhinoceroses were similar across trials $(p>0.05)$ with values of $7 \pm 2$ breaths $/ \mathrm{min}$ (control), $6 \pm 1$ breaths/min (But), $7 \pm 1$ breaths $/ \mathrm{min}$ (But+M5050), $7 \pm 1$ breaths $/ \mathrm{min}\left(\mathrm{But}+\mathrm{O}_{2}\right)$ and $7 \pm$ 2 breaths/min (But $+\mathrm{M} 5050+\mathrm{O}_{2}$ ) (Figure 1c and Figure 2c)., which is much lower than the reported normal respiratory rates in standing, unsedated white rhinoceroses (16-23 breaths/min [Citino \& Bush 2007]). The rhinoceroses' respiratory rates then changed over time in both sets of trials $\left(F_{(3,21)}=14.76, p<0.0001\right.$ [trials without oxygen] and $F_{(3,21)}=$ $9.85, p=0.0003$ [trials with oxygen]). However, the different treatment interventions did not lead to differences in respiratory rates in the rhinoceroses $\left(F_{(2,14)}=3.4, p=0.06\right.$ [trials without oxygen] and $F_{(2,14)}=0.1449, p=0.87$ [trials with oxygen]), except at $10 \mathrm{~min}$, where the post-hoc test indicates that But $+\mathrm{O}_{2}$ led to improved respiratory rates compared to $\mathrm{But}+\mathrm{M} 5050+\mathrm{O}_{2}(p<0.05)$. At $20 \mathrm{~min}$, the rhinoceroses had respiratory rates that were similar to those at $5 \mathrm{~min}$ across all trials, namely $6 \pm 2$ breaths $/ \mathrm{min}$ (control), $7 \pm 1$ breaths $/ \mathrm{min}$ (But), $7 \pm 2$ breaths/min (But+M5050), $6 \pm 1$ breaths $/ \mathrm{min}$ (But $+\mathrm{O}_{2}$ ) and $6 \pm 1$ breaths $/ \mathrm{min}\left(\mathrm{But}+\mathrm{M} 5050+\mathrm{O}_{2}\right.$ ).

\section{Field study}

Similar to the boma study, chemical immobilisation with a combination of etorphine, azaperone and hyaluronidase led to severe hypoxaemia in all the rhinoceroses at $5 \mathrm{~min}$ postrecumbency $\left(\mathrm{P}_{\mathrm{a}} \mathrm{O}_{2}=35 \mathrm{mmHg} \pm 7 \mathrm{mmHg}\right.$ in the But $+\mathrm{O}_{2}$ trial and $34 \mathrm{mmHg} \pm 6 \mathrm{mmHg}$ in the But $+\mathrm{M} 5050+\mathrm{O}_{2}$ trial) (Figure 3a). Both combinations of the partial-opioid antagonists combined with oxygen led to an immediate, positive effect on oxygenation. At $10 \mathrm{~min}$, which is $4 \mathrm{~min}$ after the treatments, $\mathrm{P}_{\mathrm{a}} \mathrm{O}_{2}$ was $69 \mathrm{mmHg} \pm 7 \mathrm{mmHg}(p<0.0001$, $5 \mathrm{~min}$ vs $10 \mathrm{~min})$ and $62 \mathrm{mmHg} \pm 10 \mathrm{mmHg}(p=0.009$, $5 \mathrm{~min}$ vs. $10 \mathrm{~min}$ ) in the $\mathrm{But}+\mathrm{O}_{2}$ and $\mathrm{But}+\mathrm{M} 5050+\mathrm{O}_{2}$ trials, respectively. Indeed, $\mathrm{P}_{\mathrm{a}} \mathrm{O}_{2}$ was greater at all time points following the interventions, compared to that at $5 \mathrm{~min}$, in both trials $\left(F_{(4,100)}=25.49, p<0.0001\right)$ and there were no differences in the responses to the different treatments $\left(F_{(1,100)}=1.37\right.$, $p=0.244)$. Oxygenation in the rhinoceroses remained elevated throughout the immobilisation period with $\mathrm{P}_{\mathrm{a}} \mathrm{O}_{2}$ values at $25 \mathrm{~min}$ of $81 \mathrm{mmHg} \pm 27 \mathrm{mmHg}\left(\mathrm{But}+\mathrm{O}_{2}\right)$ and $80 \mathrm{mmHg} \pm$ $20 \mathrm{mmHg}\left(\right.$ But $\left.+\mathrm{M} 5050+\mathrm{O}_{2}\right)$.

Together with the hypoxaemia, the rhinoceroses were also hypercapnic $5 \mathrm{~min}$ after they became recumbent, with $\mathrm{P}_{\mathrm{a}} \mathrm{CO}_{2}$ values of $65 \mathrm{mmHg} \pm 8 \mathrm{mmHg}\left(\mathrm{But}+\mathrm{O}_{2}\right)$ and $69 \mathrm{mmHg} \pm 7 \mathrm{mmHg}$ (But $+\mathrm{M} 5050+\mathrm{O}_{2}$ ) (Figure 3b). The $\mathrm{P}_{\mathrm{a}} \mathrm{CO}_{2}$ in the rhinoceroses that received $\mathrm{But}+\mathrm{O}_{2}$ then decreased $\left(F_{(1,100)}=26.04, p<0.0001\right)$ to the extent that $\mathrm{P}_{\mathrm{a}} \mathrm{CO}_{2}$ was lower $(p<0.05)$ than at $5 \mathrm{~min}$ at 10,15 and $20 \mathrm{~min}$, but not at $25 \mathrm{~min}$. In the But $+\mathrm{M} 5050+\mathrm{O}_{2}$ trial, $\mathrm{P}_{\mathrm{a}} \mathrm{CO}_{2}$ values were statistically similar at all time points $(p>0.05)$. At $10 \mathrm{~min}(p<0.01)$ and $15 \mathrm{~min}(p<0.05)$, the $\mathrm{P}_{\mathrm{a}} \mathrm{CO}_{2}$ in the rhinoceroses that received $\mathrm{But}+\mathrm{O}_{2}$ was lower than in those that received But $+\mathrm{M} 5050+\mathrm{O}_{2}$. At $10 \mathrm{~min}, \mathrm{P}_{\mathrm{a}} \mathrm{CO}_{2}$ values in the rhinoceroses were $58 \mathrm{mmHg} \pm 9 \mathrm{mmHg}\left(\mathrm{But}+\mathrm{O}_{2}\right)$ and $64 \mathrm{mmHg} \pm 7 \mathrm{mmHg}\left(\mathrm{But}+\mathrm{M} 5050+\mathrm{O}_{2}\right)$. By the end of the immobilisation period, $\mathrm{P}_{\mathrm{a}} \mathrm{CO}_{2}$ values in the rhinoceroses were $60 \mathrm{mmHg} \pm 7 \mathrm{mmHg}$ and $63 \mathrm{mmHg} \pm 6 \mathrm{mmHg}$ in the But $+\mathrm{O}_{2}$ and But $+\mathrm{M} 5050+\mathrm{O}_{2}$ trials, respectively.

Corresponding with the observed hypercapnia, the respiratory rates were also different between treatments $\left(F_{(1,100)}=23.72, p<0.0001\right)$ and across time $\left(F_{(4,100)}=7.98\right.$, $p<0.0001$ ) (Figure 3c). Immobilisation caused hypopnea in all the rhinoceroses at $5 \mathrm{~min}(13 \pm 2$ breaths $/ \mathrm{min}$ in both trials). But $+\mathrm{O}_{2}$ administration led to increased respiratory rates in the rhinoceroses compared to those that received But $+\mathrm{M} 5050+\mathrm{O}_{2}$ at $10 \mathrm{~min}(p<0.01)$ and $15 \mathrm{~min}(p<0.05)$. But $+\mathrm{M} 5050+\mathrm{O}_{2}$ administered to the rhinoceroses led to a decrease in respiratory rates at $20 \mathrm{~min}(9 \pm 2$ breaths $/ \mathrm{min}$, $p<0.05)$ and $25 \mathrm{~min}(9 \pm 3$ breaths $/ \mathrm{min}, p<0.05)$ compared 

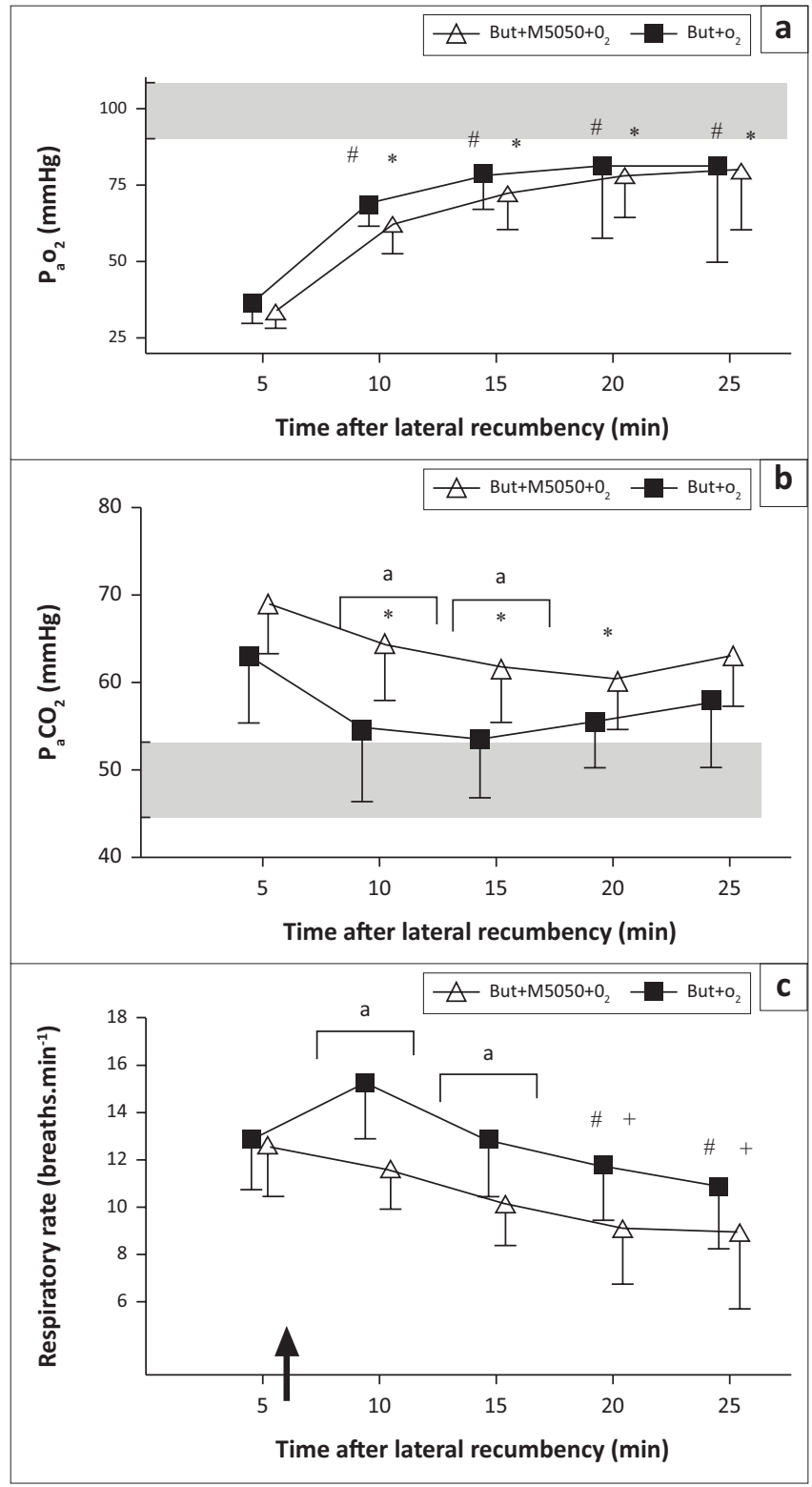

The black arrow indicates the time at which the partial antagonists were administered and oxygen insufflation initiated.

Note: ' $a$ ', indicates the time points at which the values in the But $+\mathrm{O}_{2}$ group differed from those in the But $+\mathrm{M} 5050+\mathrm{O}_{2}$ group.

The shaded area represents the range of normal values in standing, unrestrained white rhinoceros.

*, Values in the But $+\mathrm{O}_{2}$ trial that differ from pre-intervention values $(5 \mathrm{~min})$.

+ , Values in the But $+\mathrm{O}_{2}$ trial that differ from values at $10 \mathrm{~min}$.

\#, Values in the But+M5050+O trial that differ from pre-intervention values ( $5 \mathrm{~min}$ ).

Source: Citino, S.B. \& Bush, M., 2007 'Reference cardiopulmonary physiologic parameters for standing, unrestrained white rhinoceroses (Ceratotherium simum)', Journal of Zoo and Wildlife Medicine 38, 375-379. https://doi.org/10.1638/2006-0007R1.1

FIGURE 3: Field study. (a) Partial pressure of arterial oxygen $\left(P \mathrm{O}_{2}\right)$, (b) partia pressure of arterial carbon dioxide $\left(\mathrm{P}_{\mathrm{a}} \mathrm{CO}_{2}\right)$ and (c) respiratory rate of fieldimmobilised rhinoceros given intravenous butorphanol + oxygen insufflation (But $+\mathrm{O}_{2} n=14$ ) or intravenous butorphanol + diprenorphine + oxygen insufflation (But+M5050+O,$n=8$ ). Mean and standard deviations shown.

to that at $5 \mathrm{~min}$. On the other hand, But $+\mathrm{O}_{2}$ led to an initial clinically relevant but statistically insignificant increase in the respiratory rates of the rhinoceroses at $10 \mathrm{~min}(15 \pm 2$ breaths / $\mathrm{min}$ at $10 \mathrm{~min}$ vs. $13 \pm 2$ breaths $/ \mathrm{min}$ at $5 \mathrm{~min}, p=0.07$ ), which was followed by a gradual decrease to the extent that the respiratory rates at $20 \mathrm{~min}(12 \pm 2$ breaths $/ \mathrm{min}, p<0.01)$ and $25 \mathrm{~min}(11 \pm 3$ breaths $/ \mathrm{min}, p<0.0001)$ were lower than the respiratory rates at $10 \mathrm{~min}$.

\section{Discussion}

Previous work has demonstrated that butorphanol with oxygen insufflation corrects the etorphine-induced hypoxaemia in boma-immobilised white rhinoceroses (Haw et al. 2014) and significantly reduces the severity of the hypoxaemia in field-immobilised white rhinoceroses to a clinically acceptable level (Haw et al. 2015). Here, we show that the same positive effect on blood gases can be achieved if butorphanol is replaced with a lower dose of butorphanol combined with diprenorphine. Similar to findings in our previous study (Haw et al. 2014), these opioid agonistantagonists, at the doses used, only moderately improved blood oxygenation; thus, the addition of oxygen insufflation is necessary to correct the opioid-induced hypoxaemia. In the boma study described here, the partial pressure of arterial oxygenation was completely corrected with both treatments that included oxygen (But $+\mathrm{O}_{2}$ and But $+\mathrm{M} 5050+\mathrm{O}_{2}$ ), with no differences between the use of a single or combination of partial agonist-antagonist treatments. Although the interventions without oxygen (But and But+M5050) improved but did not correct the etorphine-induced hypoxaemia, the responses to the treatments were clinically similar in the boma trials. Similarly, in field-immobilised rhinoceroses, there were no differences in the rhinoceroses' $\mathrm{P}_{\mathrm{a}} \mathrm{O}_{2}$ values between the two treatments $\left(\mathrm{But}+\mathrm{O}_{2}\right.$ and But $+\mathrm{M} 5050+\mathrm{O}_{2}$ ), but the blood oxygenation was not completely corrected despite the animals receiving oxygen insufflation, although it was significantly improved, leading to a clear clinical benefit from the treatments.

The effects that the two partial antagonist treatments combined with oxygen had on the $\mathrm{P}_{\mathrm{a}} \mathrm{CO}_{2}$ were not as profound as that on the $\mathrm{P}_{\mathrm{a}} \mathrm{O}_{2}$. However, treatments led to a reduction in hypercapnia and there were no differences between the two treatments in the boma-immobilised rhinoceroses. This finding is consistent with previous work, which demonstrated that butorphanol with oxygen insufflation improved but did not fully correct etorphineinduced hypercapnia in boma-immobilised rhinoceroses (Haw et al. 2014). Also, consistent with previous findings (Haw et al. 2014), we demonstrated that the treatments without oxygen led to a more profound reduction in $\mathrm{P}_{\mathrm{a}} \mathrm{CO}_{2^{\prime}}$ compared to the treatments with oxygen in boma-immobilised rhinoceroses. High levels of inspired oxygen have been found to increase $\mathrm{P}_{\mathrm{a}} \mathrm{CO}_{2}$ levels in humans (Aboab et al. 2006; Perrin et al. 2011 Pilcher, Perrin \& Beasley 2013), horses (Marntell, Nyman \& Hedenstiernal 2005) and immobilised wildlife (Fahlman 2014) with respiratory compromise. A primary mechanism for the rise in $\mathrm{P}_{\mathrm{a}} \mathrm{CO}_{2}$ with high inspired oxygen is likely worsening ventilation-perfusion mismatch caused by absorption atelectasis (Aboab et al. 2006; Marntell et al. 2005). Other proposed mechanisms could include a release of hypoxic vasoconstriction (increasing alveolar dead space), a decrease in the hypoxic ventilator drive (decreasing ventilation) or the Haldane effect (displacement of $\mathrm{CO}_{2}$ from haemoglobin into plasma) as a result of increasing $\mathrm{PaO}_{2}$ levels (Fahlman 2014). Perhaps, titrating the oxygen flow rate to achieve optimum $\mathrm{P}_{\mathrm{a}} \mathrm{O}_{2}$ and $\mathrm{P}_{\mathrm{a}} \mathrm{CO}_{2}$ levels, as recommended 
for humans with respiratory disorders (Pilcher et al., 2013), would result in lower $\mathrm{P}_{\mathrm{a}} \mathrm{CO}_{2}$, while maintaining sufficient $\mathrm{P}_{\mathrm{a}} \mathrm{O}_{2}$ in white rhinoceroses. In the field-immobilised rhinoceroses, this study shows that the But $+\mathrm{O}_{2}$ treatment led to a greater reduction in the hypercapnia than the But $+\mathrm{M} 5050+\mathrm{O}_{2}$ treatment. Concerning respiratory rate, the But $+\mathrm{O}_{2}$ treatment led to greater respiratory rates than the But $+\mathrm{M} 5050+\mathrm{O}_{2}$ treatment in both boma- and fieldimmobilised rhinoceroses. However, in the treatments without oxygen in boma-immobilised rhinoceroses, there were no differences in respiratory rate responses between the But and But+M5050 treatments at the doses used.

Both butorphanol and diprenorphine are opioid agonistantagonists. However, diprenorphine is known to have greater antagonistic effects than butorphanol (Burroughs, Meltzer \& Morkel 2012b). Indeed, diprenorphine (M5050 ${ }^{\circledR}$ ) is supplied with etorphine $\left(\mathrm{M}^{\circledR}{ }^{\circledR}\right)$ by its current manufacturer, Voluplex, and is registered as the standard antidote for etorphine-induced immobilisation. To reverse the effects of etorphine, diprenorphine is given at $2-3 \mathrm{mg}$ per $\mathrm{mg}$ etorphine (Burroughs et al. 2012b; Swan 1993). In most species, diprenorphine has been the most commonly used antagonist (Burroughs et al. 2012b) and recovery times following intravenous diprenorphine administration range from a few seconds to 4 min (Swan 1993). However, it is believed that diprenorphine does have some agonistic effects, and a degree of sedation may be maintained when it is used, particularly in some species (white rhinoceros, elephant and giraffe). Therefore, it is recommended that a pure opioid antagonist, such as naltrexone, be used to reverse the effects of opioid agonists in animals that are to be released into the wild (Burroughs et al. 2012b). In white rhinoceros, diprenorphine appears to not antagonise the effects of etorphine completely and animals will remain partially narcotised for up to $8 \mathrm{~h}$ following the administration of diprenorphine (Kock et al. 1995; Rogers 1993). Whether these effects can be attributed to possible agonistic effects of diprenorphine, as has been found at kappa-receptors in the guinea-pig ileum (Traynor, Corbett \& Kosterlitz 1987), or simply poor efficacy or lower affinity of this drug to opioid receptors in this species remains to be determined.

Like butorphanol, diprenorphine has been advocated as a potential treatment to reverse the respiratory impairment effects of etorphine in immobilised white rhinoceroses. Therefore, the aim of this study was to compare the effects of butorphanol and butophanol plus diprenorphine because these treatments are currently used by veterinarians in the field to reduce the etorphine-induced respiratory impairment, but their efficacy in achieving this goal has not been rigorously evaluated or compared.

Based on anecdotal findings from the field, practitioners have suggested giving $1 \mathrm{mg}$ diprenorphine with $10 \mathrm{mg}$ butorphanol IV immediately to all white rhinoceroses (Burroughs et al. 2012a). To standardise our trial, diprenorphine and butorphanol were administered at a set ratio to the dose of etorphine used in the immobilising dart. Therefore, $0.4 \mathrm{mg}$ diprenorphine and $3.3 \mathrm{mg}$ butorphanol per $\mathrm{mg}$ etorphine were used, which equates to about $1 \mathrm{mg}$ diprenorphine with $10 \mathrm{mg}$ butorphanol for $2 \mathrm{mg}-3 \mathrm{mg}$ etorphine administered.

The results of this study have demonstrated that the treatments But $+\mathrm{O}_{2}$ and But $+\mathrm{M} 5050+\mathrm{O}_{2}$ both elicited similar changes in respiratory responses and corrected the etorphineinduced hypoxaemia in boma-immobilised white rhinoceros. However, treatment with butorphanol+diprenorphine, at the doses used in these trials, was not as beneficial as butorphanol at the higher dosage used alone in correcting the etorphineinduced hypercapnia and hypopnoea. Our evidence shows that at certain times the rhinoceroses had higher $\mathrm{P}_{\mathrm{a}} \mathrm{CO}_{2}$ values and lower respiratory rates after But $+\mathrm{M} 5050+\mathrm{O}_{2}$, compared to those after But $+\mathrm{O}_{2}$. Thus, although both treatments had the same effect on the rhinoceroses' $\mathrm{P}_{\mathrm{a}} \mathrm{O}_{2}$, the treatment with diprenorphine did not always improve $\mathrm{P}_{\mathrm{a}} \mathrm{CO}_{2}$ as well as the treatment without diprenorphine, where a greater dose of butorphanol was used. This discrepancy in the treatments' effects on $\mathrm{P}_{\mathrm{a}} \mathrm{CO}_{2}$ may partly be explained by uncontrolled confounders. One possible limitation of the study is that the But $+\mathrm{M} 5050+\mathrm{O}_{2}$ group had a smaller sample size than that of the But $+\mathrm{O}_{2}$ group. Another possible explanation could be that when butorphanol+diprenorphine is used in the field, compared to butorphanol alone, the lower dose of butorphanol or the differing antagonist effects of diprenorphine in this combination may have a better effect on antagonising other pathophysiological effects of etorphine that cause hypoxaemia (Buss et al. 2018; Meyer et al. 2015), with less of an effect on ventilation or the production of carbon dioxide from metabolism.

\section{Conclusion}

Regardless of the above-mentioned potential confounders, the results of this study have shown that using supplemental oxygen with a combination of low-dose butorphanol and diprenorphine offers no advantage, other than a potential cost-saving benefit, in alleviating etorphine-induced respiratory impairment compared to butorphanol (15 mg per mg etorphine) with oxygen. Some veterinarians are using diprenorphine on its own to reverse the etorphineinduced respiratory impairment in the white rhinoceros. Based on the results of these trials, it may be worthwhile to determine if a higher dose of diprenorphine used alone could offer any physiological benefit over butorphanol alone. However, this study confirms that arterial oxygen levels can be restored to clinically acceptable values in immobilised white rhinoceroses administered either But $+\mathrm{O}_{2}$ or But $+\mathrm{M} 5050+\mathrm{O}_{2}$ at the doses used in this study.

\section{Acknowledgements}

The authors thank the staff of the SANParks Veterinary Wildlife Services for dedicated support and assistance with experimental procedures. In particular, they thank Marius Kruger for managing the capture team and Jennifer Hofmeyr, Nomkhosi Mathebula and Guy Hausler for field and laboratory assistance. 


\section{Competing interests}

The authors declare that they have no competing interests that could be perceived as prejudicing the impartiality of the research reported.

\section{Authors contributions}

A.F., A.H., L.M., M.H., P.B. and M.M. were responsible for study conception and design. Data collection and experimental procedures were performed by A.F., A.H., L.M., M.H., P.B. and M.M. Data analysis was conducted by A.H., A.F. and L.M. A.H. and L.M. made the first draft. A.F., A.H., M.H., P.B., M.M. and P.K. provided comments on the draft and final approval for the article.

\section{Funding information}

The South African National Research Foundation, the South African Medical Research Council, the International Rhino Foundation, Disney's Animal Programs and Environmental Initiatives, SANParks and the University of the Witwatersrand and the University of Pretoria provided equipment, drugs and financial support for the research. The South African Veterinary Association paid for the article page fees.

\section{Disclaimer}

The views expressed in this article are those of the authors.

\section{References}

Aboab, J., Jonson, B., Kouatchet, A., Taille, S., Niklason, L. \& Brochard, L., 2006, ‘Effect of inspired oxygen fraction on alveolar derecruitment in acute respiratory distress syndrome', Intensive Care Medicine 32, 1979-1986. https://doi.org/10.1007/ s00134-006-0382-4

Alford, B.T., Burkhart, R.L. \& Johnson, W.P., 1974, 'Etorphine and diprenorphine as immobilizing and reversing agents in captive and free-ranging mammals', Journal of the American Veterinary Medical Association 164, 702-705.

Boardman, W.S.J., Caraguel, C.G.B., Raath, J.P. \& Van Zijll Langhout, M., 2014, Intravenous butorphanol improves cardiopulmonary parameters in gameranched white rhinoceroses (Ceratotherium simum) immobilized with etorphine ranched white rhinoceroses (Ceratotherium simum) immobilized with etorphine
and azaperone', Journal of Wildlife Diseases 50, 849-857. https://doi.org/ and azaperone', Journal
$10.7589 / 2013-12-327$

Burroughs, R., Hofmeyr, M., Morkel, P., Kock, M.D., Kock, R. \& Meltzer, D., 2012a, 'Chemical immobilization - Individual species requirements', in M.D. Kock, 'Chemeltzer \& R. Burroughs (eds.), Chemical and physical restraint of wild animals, 2nd edn., pp. 223-234, IWVS (Africa), Greyton.

Burroughs, R., Meltzer, D. \& Morkel, P., 2012b, 'Applied pharmacology', in M.D. Kock, D. Meltzer \& R. Burroughs (eds.), Chemical and physical restraint of wild animals, 2nd edn., pp. 53-80, IWVS (Africa), Greyton.
Bush, M., Raath, J.P., Grobler, D. \& Klein, L., 2004, 'Severe hypoxaemia in fieldanaesthetised white rhinoceros (Ceratotherium simum) and effects of using tracheal insufflation of oxygen', Journal of the South African Veterinary Association 72, 79-84. https://doi.org/10.4102/jsava.v75i2.457

Buss, P., Miller, M., Fuller, A., Haw, A., Stout, E., Olea-Popelka, F. et al., 2018, 'Postinduction butorphanol administration alters oxygen consumption to improve blood gases in etorphine-immobilized white rhinoceros', Veterinary Anaesthesia and Analgesia 45, 57-67. https://doi.org/10.1016/j.vaa.2017.03.008

Citino, S.B. \& Bush, M., 2007 'Reference cardiopulmonary physiologic parameters for standing, unrestrained white rhinoceroses (Ceratotherium simum)', Journal of Zoo and Wildlife Medicine 38, 375-379. https://doi.org/10.1638/2006-0007R1.1

Fahlman, A., 2008, 'Advances in wildlife immobilisation and anaesthesia: Clinical and physiological evaluation in selected species', PhD thesis, Swedish University of Agricultural Sciences.

Fahlman, A., 2014, 'Oxygen therapy', in G. West, D. Heard \& N. Caulkett (eds.), Zoo animal and wildlife immobilization and anesthesia, 2nd edn., pp. 69-81, John Wiley \& Sons, Inc., New York.

Haw, A., Hofmeyr, M., Fuller, A., Buss, P., Miller, M., Fleming, G. et al., 2014, 'Butorphanol with oxygen insufflation corrects etorphine-induced hypoxaemia in chemically immobilized white rhinoceros (Ceratotherium simum)', BMC Veterinary Research 10, 253. https://doi.org/10.1186/s12917-014-0253-0

Haw, A., Hofmeyr, M., Fuller, A., Buss, P., Miller, M., Fleming, G. et al., 2015 'Butorphanol with oxygen insufflation improves cardiorespiratory function in field-immobilised white rhinoceros (Ceratotherium simum)', Journal of the South African Veterinary Association 86, E1-E10.

Kock, M.D., Morkel, P., Atkinson, M. \& Foggin, C., 1995, 'Chemical immobilisation of freeranging white rhinoceros (Ceratotherium simum simum) in Hwange and Matobo National Parks, Zimbabwe, using combinations of etorphine (M99), fentanyl, xylazine and detomidine', Journal of Zoo and Wildlife Medicine 26, 207-219.

Marntell, S., Nyman, G. \& Hedenstierna, G., 2005, 'High inspired oxygen concentrations increase intrapulmonary shunt in anaesthetized horses', Veterinary Anaesthesia and Analgesia 32, 338-347. https://doi.org/10.1111/j.1467-2995.2005.00199.x

Meyer, L., Hetem, R., Mitchell, D. \& Fuller, A., 2015, 'Hypoxia following etorphine administration in goats (Capra hircus) results more from pulmonary hypertension than from hypoventilation' BMC Veterinary Research 11, 18. https://doi.org/ 10.1186/s12917-015-0337-5

Miller, M., Buss, P., Joubert, J., Mathebula, N., Kruger, M., Martin, L. et al., 2013, 'Use of butorphanol during immobilisation of free-ranging white rhinoceros (Ceratotherium simum)', Journal of Zoo and Wildlife Medicine 44, 55-61. https:// doi.org/10.1638/1042-7260-44.1.55

Miller, M., Kruger, M., Kruger, M., Olea-Popelka, F. \& Buss, P., 2016, 'A scoring system to improve decision-making and outcomes in the adaptation of recently captured white rhinoceros (Ceratotherium simum) to captivity', Journal of Wildlife Diseases 52, S78-S85. https://doi.org/10.7589/52.2S.S85

Perrin, K., Wijesinghe, M., Healy, B., Wadsworth, K., Bowditch, R., Bibby, S. et al., 2011 'Randomised controlled trial of high concentration versus titrated oxygen therapy in severe exacerbations of asthma', Thorax 66, 937-941. https://doi.org/10.1136/ thx.2010.155259

Pilcher, J., Perrin, K. \& Beasley, R., 2013, 'The effect of high concentration oxygen therapy on $\mathrm{PaCO}_{2}$ in acute and chronic respiratory disorders', Translationa Respiratory Medicine 1, 8. https://doi.org/10.1186/2213-0802-1-8

Rogers, P.S., 1993, 'Chemical capture of white rhinoceros (Ceratotherium simum)', in A.A. McKenzie (ed.), The capture and care manual, pp. 512-533, Wildlife Decisions Support Services and The South African Veterinary Foundation, Pretoria, South Africa.

Swan, G.E., 1993, 'Drugs used for the immobilization, capture and translocation of wild animals', in A.A. McKenzie (ed.), The capture and care manual, pp. 3-98,
Wildlife Decision Support Services and The South African Veterinary Foundation, Wildlife Decision Supp
Pretoria, South Africa.

Traynor, J.R., Corbett, A.D. \& Kosterlitz, H.W., 1987, 'Diprenorphine has agonist activity at opioid k-receptors in the myenteric plexus of the guinea-pig ileum' European Journal of Pharmacology 137, 85-89. https://doi.org/10.1016/0014-2999(87)90185-3

Wenger, S., Boardman, W., Buss, P., Govender, D. \& Foggin, C., 2007, 'The cardiopulmonary effects of etorphine, azaperone, detomidine, and butorphanol in field-anaesthetized white rhinoceroses (Ceratotherium simum)', Journal of Zoo and Wildlife Medicine 38, 380-387. https://doi.org/10.1638/2006-0038R.1 